\title{
The Exploration of Comprehensive Reform of Application-Oriented Education for Undergraduates Majored in Mechatronics Engineering
}

\author{
Shuzhen Yang \\ College of Engineering \\ Shanghai Second Polytechnic University \\ Shanghai, China \\ szyang@sspu.edu.cn
}

\author{
Fangfang Sun \\ College of Engineering \\ Shanghai Second Polytechnic University \\ Shanghai, China \\ ffsun@sspu.edu.cn
}

\begin{abstract}
Application-oriented education for undergraduates receives more and more attentions of colleges and universities along with the gradual switch of Chinese higher education from large-scale development to intensive development with its focus on education quality. Now lots of colleges and universities obtained approval and already started developing applicationoriented education for undergraduates. Taking the development of application-oriented education for undergraduates majored in mechatronics engineering in Shanghai Second Polytechnic University, this paper aims to provide new thoughts to the comprehensive reform of application-oriented education for undergraduates by explaining the main objectives and methods of this development in general and relative reforming measures and paths in detail from the perspective of the content and approaches of education with considerations of the features of mechatronics major.
\end{abstract}

Keywords-application-oriented education for undergraduates; higher education reform; talents cultivating; mechatronics

\section{INTRODUCTION}

At present, Chinese higher education transits into a new stage of intensive development with its focus on the improvement of education quality from the former large-scale development, namely, a transition from going big to being strong, which in turn brought new requirements to the higher education reform. Since majors are carriers for talents cultivating in colleges and universities as well as footholds to promote the higher education reform and improvement of education quality, their development and performance represent the quality and features of talents cultivating in colleges and universities. In the "12th Five-Year Plan" period, the Ministry of Education launched and promoted the establishment of "pilots of comprehensive reform for undergraduate majors" to instruct colleges and universities to proactively meet the demands of national strategic development and local economic and social development, optimize their disciplinary structure, enhance the intensive construction of undergraduate majors and to make innovations in talents cultivating. Expecting to achieve a better effect in the comprehensive reforms for undergraduate majors, colleges and universities must determine a scientific and reasonable general reforming objective, develop and implement a practical reform program based on their educational positioning, disciplines, and the requirements of industrial and local economic development, as well as their existing disciplinary conditions and educational features. This paper takes the reform of application-oriented education for undergraduates majored in mechatronics engineering in Shanghai Second Polytechnic University as an example to discuss the specific objectives, general methods and major achievements of comprehensive reforms of application-oriented education for undergraduates in different majors.

\section{THE CONSTRUCTIVE OBJECTIVES OF COMPREHENSIVE REFORMS OF EDUCATION FOR UNDERGRADUATE MAJORS}

According to the International Standard Classification of Education released by UNESCO, level 5 of higher education can be divided into 5A1, 5A2 and 5B types, respectively refers to the cultivation of academic and research talents, applicationoriented trained talents and practical vocational and technical talents. Academic undergraduate education, applicationoriented undergraduate education and higher vocational college are respectively specialized in above mentioned three categories[1]. Different from other two types of education, application-oriented undergraduate education has its own objectives, standards and educational system in talents cultivating. The mechatronics engineering major of our school is among the first batch of pilot majors of application-oriented undergraduate education of Shanghai, also a major project receiving great focus during its development. Though our school achieved many successes in disciplinary construction and reform of talents cultivating in several education reforms, including development of key majors, construction of key laboratories, establishment of an educational high land in Shanghai and key reforming project at the undergraduate level in Shanghai, some underlying problems were gradually revealed along with the deepening of education reform, such as unification of cultivating mode, unreasonable curriculum and faculty and very little effect produced by incentives. All these issues have significant affect and limitation on the improvement of the quality of talents cultivating. Therefore, we took this opportunity to adopt a series of measures to deepen the comprehensive education reform in order to solve above mentioned issues that we may encounter in our practice of education. We determine to be a leading institution in this field among all colleges and universities by establishing innovative ways for the cultivation of application-oriented technical talents, training personalized application-oriented talents to meet various demands of enterprises, refining this major into three specific directions, which were numerical control, control of electromechanical devices and dynamic monitoring of electromechanical devices. 


\section{METHOD STATEMENT FOR THE COMPREHENSIVE EDUCATION REFORM OF VARIOUS MAJORS}

The most essential section of every kind of education reform is the transformation in the mode of talents cultivating. While the essence of which are objectives, standards and basic methods of talents cultivating, the unification of educational philosophy and education process, also the unification of its objectives and operations. Talents cultivating has many elements, among which, the most important ones are the objectives, content and methods of education[2]. Our disciplinary reform contained adjustment in the objective (for talents cultivating), content (including cultivating system, courses and practices), and methods of education. We focused on top-level design, development of regulations and educational contents to ensure achieving our target of this reform.

\section{A. Determining the Objectives for Talents Cultivating According to the Intensive Development of Application- Oriented Education for Undergraduates and the Actual Situation of the Major}

Article 16 of Higher Education Law of the People's Republic of China points out that Regular course education shall enable students to grasp more systematically the basic theories and knowledge required by the branches of learning or specialized subjects offered, to grasp the basic skills, methods and relevant knowledge necessitated by their specialized subjects, and to acquire the preliminary ability of practical work and research in the fields of their specialized subjects. This is the objective of undergraduate education from a macroscopic viewpoint. While application-oriented education for undergraduates shall fulfill the basic requirements of the national regulations for undergraduate education but also demonstrate the unique connotation of "application-oriented education", which requires expressions of various majors from microscopic viewpoint. Application-oriented institutions at the undergraduate level shall consider more about the orientation and vocational development of the major when setting courses and determine the objectives and standards of professionals cultivating based on its academic, technical and vocational features, in order to achieve a more professional cultivation of talents with specific objectives. Therefore, the target of application-oriented education for undergraduates shall be the cultivation of application-oriented technical talents capable of working on high technologies and advanced disciplines and with positive civic virtues and professional ethics, qualified political ideologies, good physical and psychological quality, basic humanistic and scientific attainments, and refined professional qualities[3], depending on the features of every institution and its majors. We thought of an applicationoriented technical talent that is in accordance with the demands of the market at the present stage must be equipped with "solid basic knowledge, strong abilities, high qualities and diversity". The general principle of talents cultivating stresses teaching of basic theories, training of fundamental skills, enhancement of practical teaching, cultivation of students' practical ability, innovative ability and comprehensive ability, and the overall improvement of the comprehensive qualities of students. During the development and implementation of program for talents cultivating, application-oriented institutions shall fully showcase the characteristics of their undergraduate majors, take advantage of Shanghai's leading strength in advanced manufacturing, and focus on the personalized development of students to provide students with different traits and preferences with a space to display their strengths.

\section{B. Reforming the Content of Education, Enhancing the Construction of Educational Resources and Improving the Quality of Talents Cultivating}

Based on their objectives of talents cultivating, higher education colleges and universities can establish a suitable system for cultivating new-type talents, adjust their curriculum and content of education, optimize the curriculum and determine courses for every major, then, proceed to the overall development of curriculum with the courses setting as the main line

1) To Establish a System for Cultivating New-Type Talents. The system of talents cultivating took "3 Platforms" as the main body, "Quality Development System" as the supplement, and "the Credit System, Tutorial System and Monitorial System" as instruction and "Multilevel Scholarship" as incentive. All these factors cooperate and integrate with each other to constitute a whole functional system as shown in Fig.1.

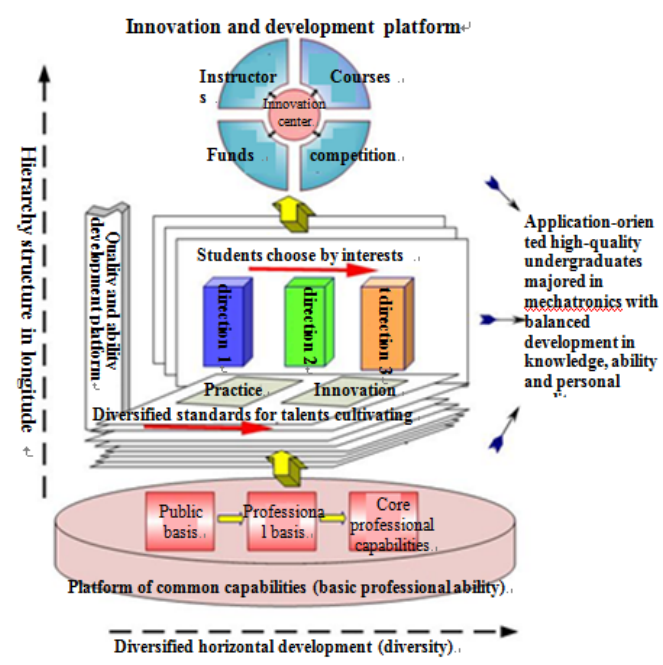

Fig. 1. System of Mechatronics Engineering Talents Cultivating

a) "3 Platforms" - Main Body

We paid special attention to establish "3 Platforms". They are a general study platform, through which students can learn some basic knowledge of their majors; a development platform for them to improve their qualities and technical literacy in various orientations students are free to choose according to their personalities and the detailed requirement of their desired positions. We also provided an innovation and development platform for students with spare capability and pursuit for further improvement. The establishment and improvement of these three platforms demand an integration of the whole curriculum system, adjustment of the setting and content of courses, reorganization of practice and education system, construction of productive, educational and research base and reforms of other sectors. 
b) Establishment of a Quality Development System Supplement

Except for instructional system and practical education system, we also need to establish a quality development system and include it into the talents cultivating program. The setup of an education system with management by project, credit system and normalized operation is an important factor to cultivate application-oriented talents. Courses included in the quality development system are required and compulsory. Their credits will be included in the evaluation of a student's performance in school. Students cannot obtain their graduation certificate until they acquire corresponding credits in their development of professional literacy and comprehensive quality.

c) Integration of Credit System, Tutorial System and Monitorial System - Personalized Instruction

We further deepened the reform of credit system by wholly adopting credit system and practicing flexible learning, loosening the limit to the period of schooling, allowing students to graduate early or late, and giving some courses equivalent effects within a certain scope on trial; by increasing the proportion of innovation credits and broadening students' rights to select their own preferences; arranging excellent teachers expert in this discipline to be the tutor and selecting excellent senior students to be the monitors of junior students to effectively guide them accomplish their studies through accumulation of credits.

\section{2) To Generally Optimize the Curriculum System}

It means to establish three major curriculum systems, common curriculum, optional courses for ability development and innovation courses,

a) Common (Basic Professional Abilities) Curriculum: In this section, we cut and combined some original professional basis courses and profession courses, and increased the proportion of integrated practice which involves the application of many courses and techniques to generally improve students' ability for practical technical operation.

b) Optional Courses for Ability Development: For this subject, in addition to required courses - main and core courses required by the major - we increased some professional optional courses groups with application technologies in different industries and to establish connection with downstream technical courses for students in demand based on our comprehensive consideration of the fact that students have various distinctive personalities and students' diversified demands for vocational guidance.

c) Courses on Innovation: For students with spare capacities, we set some courses on innovation and provided them with an atmosphere for innovation. They could choose to learn some favorable courses to improve their awareness and ability for innovation. There were courses on innovation for students in every grade; for instance, students could choose to learn innovative design and practice of mechatronics, introduction of innovation in mechatronics or other common courses on innovation, according to their interests and ability.
3) To Promote the Curriculum Development with the Setting of Curriculum groups as the Main Line

The setting of curriculum groups is based on the general technical requirement of every position. It was an optimization and combination of courses, such as reorganizing and combining courses of a major into several curriculum groups according to their orientations. Curriculum groups in each orientation should focus on improving students' technical skills and occupational quality, as well as fulfill their demands for personalized development. Its final target is to extend and diversify students' ability in all levels.

a) Methods and Measures for Setting Curriculum Groups.

First, the establishment and development of curriculum groups require the setup of an education team, which shall include experts from enterprises, experts on education reform, professional leaders, core teachers, young teachers, and students if necessary. Secondly, Curriculum group has two management layers. There are "Chief Responsible Person", selected from experienced teachers, who will be responsible for the overall development and coordination, and "Curriculum Responsible Persons", in charge of the construction of their courses and promotion of cooperation among members. Thirdly, the integrated development of curriculum groups takes the requirements of typical positions as its base. We define the general framework in accordance with the technical requirements of various positions at first, and then proceed to the construction and teaching of every course, and the establishment of laboratories. An organic whole complete educational system comes into being. Finally, the development of courses within a curriculum group shall follow the general framework and requirement of the development of curriculum groups, which means to integrate courses based on the vocational requirements and operational procedure and to organize the content of courses with "projects as guidance" and "tasks as driven forces". The development of teaching program is based on actual "work situations".

b) Integration of the Educational Content and Combination of Courses.

The key point of the development of curriculum groups is the integration of the educational content and combination of courses. Many issues appeared in the operation of enterprises are very complex and require operators to utilize knowledge of various fields to analyze and to find solutions. Therefore, we must integrate our courses.

4) To Enhance the Construction of Practical Education System

In order to resolve the problems that the practice system generally focusing on training of professional skills but ignoring the improvement of students' comprehensive quality, and the methods of practical education and cultivation not suitable to for students with distinctive characteristics and different structures of knowledge, we upgraded our practice system and established a 3-dimensional practical education and cultivation system integrated "teaching of engineering 
knowledge, cultivation of engineering literacy and personal quality, and personalization and innovation" in order to cultivate students' ability to apply engineering knowledge, improve their vocational literacy and initiatives, and to promote the harmonious development of "theoretic study practice - innovation and knowledge - personal quality personalities" of students 。

To meet the requirements of a harmonious 3-dimensional development of "theoretic study - practice - innovation and knowledge - personal quality - personalities" of innovationoriented engineering talents, we divided the cultivation of practical ability into three parts:

Basic Professional Skills - practice of basic professional skills required for students majored in mechatronics engineering, including machinery, electronics, $\mathrm{CAD}$ design and manufacturing, computer technology, sensor technology, control technology, internship in metal processing and production.

Comprehensive Engineering Literacy - cultivation and practice of comprehensive ability to apply mechatronics engineering skills and of engineering literacy (including exchange, expression, communication, teamwork, team leading arts).

Personalization and Innovation - to bring the initiative of students into play and to cultivate students' ability for engineering innovation (for instance, through the setting of optional courses, small-scale manufacturing activities, Elearning and innovation projects for students).

\section{Double-Certification Education and Practice}

In accordance with the objectives and concepts, we implemented a new practical education mode - Double Certification- with in consideration of features of this major. "Double Certification" refers to academic certificate representing one's performance in theoretic study and vocational certificate demonstrating one's practical skills.

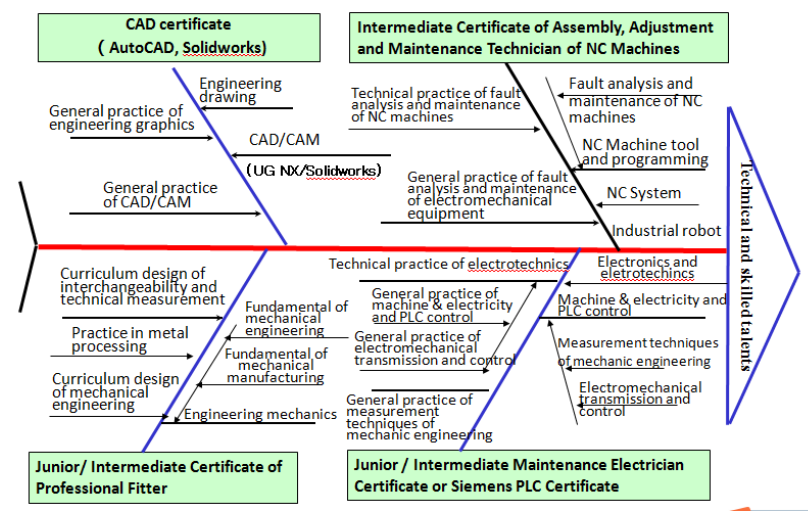

Fig. 2. Fishbone Diagram of "Double Certification" of Mechatronics Engineering Major

Since mechatronics engineering major is comprehensive undergraduate discipline integrated machinery, electricity, computer and other subjects, it is better for students in this major to obtain vocational certificates in both machinery and electricity when graduation, judging from the setting of objectives for talents cultivating and the training of core professional capabilities. In this way, they can accumulate certain experience in mechatronics for their future career. By implementing double-certification educational practice, students can obtain correspondent technical certificates after studying relative courses, practicing and receiving vocational training, in addition to their undergraduate certificate and diploma in engineering. That's how we cultivate technical talents. For details please see figure 2 .

\section{Cooperation between Higher Education Institutions and \\ Enterprises}

Another practical achievement is the cooperation between higher education institutions and enterprises. By introducing technologies into the campus, co-establishing practice base with enterprises, maintaining a long cooperative relation with enterprises through setting simulative positions, students can improve their practical operating ability and vocational skills.

\section{CONCLUSION}

Application-oriented undergraduate is a relatively new category in the classification of Chinese higher education. With the increasing deepening of social division of labors, every industry was divided into more and more categories while the requirements to persons serving relative positions have changed. Except for a certain theoretical basis, students would need to be equipped with abilities for practical operation in special works and positions and for quickly dealing with and solving actual problems. Based on the survey on mechatronics engineering major and industrial demands, and the joint study about the development positioning of vocation-oriented higher education of the institutions and the requirements of Notice on Establishing Pilots of Application-Oriented Education for Undergraduates among Shanghai Colleges and Universities released by Shanghai Municipal Education Commission, this paper clearly specifies the demands for talents cultivating of enterprises and industries, explores and discusses the appropriate mode of cultivating new-type talents for application-oriented education for undergraduates, i.e., the combination of production and teaching, meaning the consistency of talents cultivating standards and job requirements, the practical and training conditions in colleges and universities and the equipment levels of the frontline of production, and the educational content of curriculum system of every discipline and the productive procedure.

\section{REFERENCES}

[1] PAN Maoyuan \& WU Mei. Classification and Positioning of Colleges and Universities [J]. Fudan Education Forum, 2003, (3).

[2] ZHANG Xihou. A Brief Study on the Training of Application-Oriented Undergraduates in China [J]. Journal of Huanghe Science \& Technology College, 2008, (10).

[3] GAO Lin. Introduction of Application-Oriented Undergraduate Education. 2006. 